Sociedades Precapitalistas, vol. 7, nº 2, e024, junio 2018. ISSN 2250-5121

Universidad Nacional de La Plata.

Facultad de Humanidades y Ciencias de la Educación.

Centro de Estudios de Sociedades Precapitalistas (CESP)

\title{
Historia y literatura. A propósito de los relatos de La contienda entre Horus y Seth y La disputa de Verdad y Mentira
}

\footnotetext{
Marcelo Campagno

Universidad de Buenos Aires, Facultad de Filosofía y Letras, Instituto de Historia Antigua Oriental “Dr. Abraham Rosenvasser"/ CONICET, Instituto Multidisciplinario de Historia y Ciencias Humanas, Argentina

mcampagno@gmail.com

Cita sugerida: Campagno, M. (2018). Historia y literatura. A propósito de los relatos de La contienda entre Horus y Seth y La disputa de Verdad y Mentira. Sociedades Precapitalistas, 7(2), e024. https://doi.org/10.24215/22505121e024
} 


\title{
Historia y literatura. A propósito de los relatos de La contienda entre Horus y Seth y
}

\section{La disputa de Verdad y Mentira}

History and Literature. On The Contendings of Horus and Seth and Truth and Falsehood

\author{
Marcelo Campagno \\ Universidad de Buenos Aires, Facultad de Filosofia y Letras, Instituto \\ de Historia Antigua Oriental "Dr. Abraham Rosenvasser", \\ CONICET, Instituto Multidisciplinario de Historia y Ciencias \\ Humanas,Argentina mcampagno@gmail.com
}

\section{RESUMEN:}

La contienda entre Horus y Seth (Papiro Chester Beatty I) y La disputa de Verdad y Mentira (Papiro Chester Beatty II) -dos de los textos más significativos de la literatura egipcia del Reino Nuevo- presentan un destacado conjunto de características comunes. Aquí se considerarán dos cuestiones relacionadas con esa notable proximidad entre tales textos. Por un lado, el similar argumento básico de ambos textos, que parece apuntar a dos "realizaciones" literarias de un mismo mito de base. Por el otro lado, un elemento específico del contenido de ambos textos, la búsqueda de soluciones judiciales para los conflictos entre los principales protagonistas, que puede conectarse con la importancia de las "lógicas" del parentesco y del Estado tanto en la organización interna de estos textos como en la estructuración social del Antiguo Egipto. Tales consideraciones se apartan de las tradicionales formas evhemeristas de interpretar los textos literarios como reflejos de acontecimientos de un pasado lejano y destacan la posibilidad de evaluar las prácticas sociales a las que esos relatos refieren. Y hay algo más: por la vía del contraste con ciertos relatos del folklore egipcio moderno, se abre una vía de sospecha acerca de otra dimensión histórica de amplia escala, que apunta a continuidades en los imaginarios sociales, que asoman incluso más persistentes que el propio dispositivo religioso al que remiten los dos textos antiguos. Palabras ClaVe: Literatura egipcia antigua, Horus, Seth, Parentesco, Estado, Folklore.

\section{ABStRACT:}

The Contendings of Horus and Seth (Papyrus Chester Beatty I) and Truth and Falsehood (Papyrus Chester Beatty II) - two of the most significant texts in New Kingdom Egyptian literature - show an outstanding set of common characteristics. Here I will consider two issues related to that remarkable proximity between such texts. On the one hand, the similar basic argument of both texts, that seems to point to two literary "realizations" of the same basic myth. On the other hand, a specific element of the content of both texts, the search for judicial solutions for conflicts between the main protagonists, which can be connected with the importance of the "logics" of kinship and the state in the internal organization of these texts as well as in the social structuring of Ancient Egypt. Such considerations depart from the traditional euhemerist ways of interpreting literary texts as reflecting events from the distant past and highlight the possibility of evaluating the social practices to which these stories refer. And there is something else: through the contrast with certain accounts of modern Egyptian folklore, another long-term historical dimension seems to emerge, which points to continuities in social imaginaries that appear even more persistent than the religious framework to which the two ancient texts refer.

KEYwORDS: Ancient Egyptian Literature, Horus, Seth, Kinship, Estate, Folk.

\section{INTRODUCCIÓN}

El investigador egipcio Hasan El-Shamy ha puesto de manifiesto una relación que no suele ser considerada ni por sus pares folkloristas ni por los egiptólogos: la que puede establecerse entre ciertos relatos de la tradición literaria y oral del Egipto moderno y del mundo árabe, por un lado, y la narrativa mitológica del Antiguo Egipto, por otro (El Shamy, 1980: 261-264; 2002: xxx; 2006: 34-38) ${ }^{1}$. Hay una referencia que aquí nos interesa particularmente. Según el autor, un relato egipcio moderno plantea el siguiente argumento: "Verdad y Mentira comparten una granja. Mediante engaños, Mentira obtiene la parte de los beneficios de Verdad, luego su tierra, luego su casa, y finalmente quiere hacer que Verdad abandone la aldea. Acuerdan en preguntar al 
primer hombre que encuentren para que juzgue su caso. El árbitro establece: "Verdad debe abandonar la aldea y Mentira debe quedarse"." (El Shamy, 1980: 262). Ciertamente, como plantea El-Shamy, esta narración oral egipcia moderna es reminiscente de un tema recurrente en lo que se conoce como literatura egipcia antigua, especialmente en los textos correspondientes al Reino Nuevo, que consiste en una disputa entre sus dos principales protagonistas, descriptos a partir de rasgos antagónicos ${ }^{2}$. Si bien el tipo de disputa y las características de los adversarios pueden variar radicalmente, hay dos de ellos que mantienen una semejanza mayor con el relato moderno, tanto por la caracterización de los antagonistas como por el hecho de que el conflicto se somete a la autoridad de un tercero: se trata de los textos que los egiptólogos denominan $L a$ contienda entre Horus y Seth (papiro Chester Beatty I) ${ }^{3}$ y Verdad y Mentira (papiro Chester Beatty II) ${ }^{4}$.

No pretendo ingresar aquí en las complejas y difíciles relaciones entre literatura mitológica antigua y tradición oral moderna. En cambio, me interesa considerar, brevemente, dos cuestiones de diverso calibre que se relacionan con la proximidad argumental que se advierte entre los relatos de La contienda entre Horus y Seth y de Verdad y Mentira. Quizás las razones de la proximidad entre ambas narraciones antiguas iluminen, siquiera tenuemente, las posibles relaciones lejanas entre tales textos antiguos y el referido relato de la tradición oral.

\section{DEL Mito Y SUS NARRACIONES}

Veamos, ante todo, las características argumentales de ambos relatos. La contienda entre Horus y Seth constituye una de las versiones más ricas de cuantas se disponen acerca de los conflictos entre ambos dioses por acceder a la realeza egipcia. Las acciones se sitúan aquí en un escenario eminentemente judicial: en efecto, Horus y Seth comparecen ante la Enéada de los dioses presidida por Atum-Ra, que debe establecer si el oficio vacante tras el asesinato de Osiris corresponde a su joven hijo -menor de edad- o a su hermano cuyo principal atributo es su fuerza-. Los procedimientos se extienden interminablemente, debido a que Seth rechaza de modo constante los tibios intentos de la Enéada por favorecer la causa de Horus. En el ínterin, se suceden diversos episodios, que incluyen pruebas de resistencia y destreza física a las que se somete a ambos protagonistas, así como distintas estratagemas -que incluyen todo tipo de artimañas- para alcanzar la anhelada realeza, en las que tanto participan Horus y Seth como la diosa Isis, madre y enérgica partidaria del dios-halcón. Y cuando todo parece indicar que no habrá modo de resolver la disputa, la intervención de Osiris precipita el final. Desde el inframundo, exige que sea su hijo Horus quien lo suceda en el oficio real y, luego de un contrapunto epistolar con Atum-Ra, la Enéada admite el derecho de Horus, y su presidente dispone que Seth sea aprisionado y que su rival sea consagrado como rey de Egipto ${ }^{5}$.

En cuanto al relato de Verdad y Mentira, mucho más breve y fragmentario, presenta una primera escena reconocible en la que los hermanos Verdad y Mentira ${ }^{6}$ comparecen ante la Enéada, que falla a favor del segundo en un pleito que -al parecer- se entabla en relación con un cuchillo de proporciones y cualidades extraordinarias que habría poseído Mentira y que Verdad, su hermano mayor, habría dañado o extraviado. Comoquiera que fuera, a instancias de Mentira, la Enéada procede a cegar a Verdad y a establecerlo como portero de la casa de Mentira. Tiempo después, el beneficiado en el pleito intentará eliminar completamente a Verdad, pero éste evade tal destino y es finalmente admitido como portero de la casa de una dama (cuyo nombre está perdido), la cual, apasionada por Verdad, concebirá un hijo con él. Pasado el tiempo, cuando el hijo logra conocer la identidad de su padre, decide reivindicarlo y trama un plan, que consiste en lograr que Mentira se apropie de un buey del joven. Cuando esto sucede, el hijo de Verdad presenta el caso ante la Enéada, y describe a su buey de un tamaño colosal, más grande que todo Egipto. Como la Enéada descree que pueda existir semejante buey, el joven replica que tampoco puede existir un cuchillo de las características que Mentira había descrito en el juicio anterior, y exige que se vuelva a juzgar entre Verdad y Mentira. En 
el final (muy fragmentario), todo indica que (por las menciones a un castigo al que se somete a Mentira) el hijo de Verdad logra reivindicar a su padre.

Si bien una lectura sólo atenta a la identidad de los protagonistas podría concluir que no puede haber mayor distancia que la que separa una narración acerca de los dioses de otra que parece ser un mero relato de ficción, una lectura un poco más profunda puede advertir una notable serie de características comunes en ambos textos. El antagonismo entre Horus y Seth, que, de acuerdo con el mito, es producto de un antagonismo previo entre Osiris y Seth, se ve replicado en la disputa entre Mentira y el hijo de Verdad, también resultado de la disputa previa entre Verdad y Mentira ${ }^{7}$. De hecho, tanto Osiris y Seth como Verdady Mentira se presentan como hermanos y, en ambos pares, el primero es el hermano mayor y el segundo el menor. Muy especialmente, los antagonismos de ambos relatos buscan ser resueltos de modo judicial, ante la Enéada. También en ambas narraciones, se suceden las artimañas de las dos partes. Y ambos culminan con el triunfo del hijo de quien ha sufrido la adversidad inicial (la muerte de Osiris; el cegamiento de Verdad). Aun más, con independencia de su caracterización específica, en ambos relatos aparece un cuarto participante destacado, una mujer, que es la madre del futuro campeón ${ }^{8}$. Así, los cuatro protagonistas más destacados de cada relato son equiparables (Osiris = Verdad; Seth = Mentira; Horus = hijo de Verdad; Isis = dama sin nombre), en tanto que aparece un quinto protagonista invariable (la Enéada) y la dinámica de ambos relatos describe el paso de un primer antagonismo (implícito en La contienda; explícito en Verdad y Mentira) que es sucedido por un segundo antagonismo que se resuelve con la inversión del primer resultado.

Dado este notorio conjunto de similitudes, ¿qué relación específica puede trazarse entre uno y otro texto? Por un lado, tanto el papiro Chester Beatty I, en el que se halla La contienda entre Horus y Seth, como el Chester Beatty II, que contiene el relato de Verdady Mentira fueron hallados en el mismo ámbito, formando parte del archivo de una familia de escribas que vivió en Deir el-Medina durante la época ramésida (Koenig, 1981: 41-43; Pestman 1982: 155-172; Broze, 1996: 10-11). Si bien la composición de La contienda podría ser algo más tardía -se ha indicado que corresponde a la época de ascenso al trono de Ramsés V (Dinastía XX), en tanto que el texto de Verdady Mentira se suele remitir globalmente a los tiempos de la Dinastía XIX-, es posible suponer que, en el marco de un mismo contexto sociocultural, ambos relatos hayan sido elaborados a partir de unos recursos lingüísticos y expresivos genéricamente comunes ${ }^{9}$. Más allá de estas coincidencias contextuales, sin embargo, está claro que el argumento específico de Verdad y Mentira -en tanto disputa entre "dos conceptos abstractos personificados" 10 - constituye un texto único, sin antecedentes ni correlatos posteriores conocidos; por lo contrario, La contienda es una versión del conflicto mítico entre Horus y Seth que tiene una larga serie de precedentes -las primeras referencias textuales corresponden a los Textos de las Pirámides, pero los comienzos orales probablemente se remontan a la época Predinástica- y de versiones posteriores - por ejemplo, las inscriptas en el templo de Edfu, o la que refiere Plutarco en De Iside et Osiride11 .

En este sentido, dada su precedencia temporal, parece lícito postular que es el propio ciclo mítico que reúne a Osiris, Isis, Seth y Horus el que opera como "modelo" para la elaboración de ambos relatos, tanto aquel en el que tales dioses aparecen explícitamente como aquel otro en el que sólo se retiene el esquema formal de los antagonismos constituyentes del mito. Pero, ¿es esto posible? Para intentar responder tal interrogante, es necesario tener presente la compleja cuestión de las relaciones entre mito y literatura en el marco de las antiguas narraciones egipcias.

En otra parte, y siguiendo una distinción que propone Jan Assmann, he considerado el problema de la relación entre el mito y su "realización" literaria, a partir de un análisis acerca de La contienda entre Horus y Seth (Campagno, 2004: 66-72). De acuerdo con el planteo de Assmann (1977: 7-43), en el análisis del mito, es necesario distinguir dos niveles: el del geno-texto, esto es, el del mito en sí, al que no se puede acceder de manera directa; y el del feno-texto, es decir, el de las diversas plasmaciones (religiosas, mágicas, políticas, literarias) a través de las cuales el mito se manifiesta concretamente. En esta línea de análisis, entonces, es 
lícito diferenciar el mito como práctica discursiva específica respecto de otras prácticas discursivas que, en su interfase con la primera, producen los diversos modos de expresión mítica. El propio Assmann reconoce el relato de La contienda entre Horus y Seth como una forma de realización literaria del mito. En efecto, a diferencia -por ejemplo- de las referencias al mito de Horus y Seth en los Textos de la Pirámides, de realización eminentemente religiosa, la forma del mito que aparece en el relato de La contienda es susceptible de ser reconocida a partir de los criterios de ficcionalidad, intertextualidad y recepción que Antonio Loprieno define para determinar el carácter literario de una obra ${ }^{12}$. Para Loprieno (2004: 16), el relato de La contienda se incluye en el ámbito de la mitología, definida ésta a partir de dos condiciones: "la primera es un inventario de figuras asociadas a dioses pero que pueden actuar dentro de patrones de comportamiento humanos; la segunda condición es la presencia de un discurso literario distinto de otros ámbitos de producción escrita". Así pues, La contienda entre Horus y Seth puede reconocerse como una versión literaria del mito, o si se prefiere, como un texto enmarcable en el ámbito de la literatura mitológica.

Ahora bien, dado que en Verdad y Mentira no hay referencia directa a los dioses del mito, ¿no se trata de un texto correspondiente a un género literario diferente? Y si esto es así, ¿es posible plantear un análisis de tal relato en términos similares a los que se ha utilizado para considerar La contienda entre Horus y Seth? Si bien una gran cantidad de especialistas ha subrayado las homologías entre el mito de Horus y Seth y el argumento central de Verdad y Mentira, la ausencia de los dioses en este último seguramente ha contribuido a que -a diferencia de los disensos que ha producido el status mítico o literario de La contienda ${ }^{13}$ - el texto haya sido más resueltamente adjudicado al ámbito específicamente literario. John Baines, sin embargo, ha afirmado, en referencia a los textos de la época ramésida, que Verdad y Mentira constituye una de "las narrativas «miticas» que van más lejos respecto de cualquier modelo mitico directo o punto de referencia en el mundo de los dioses" (Baines, 1996: 373) ${ }^{14}$, reponiendo así una relación - por distante que sea- entre el texto y el mito. ¿Cómo puede explicarse esta relación lejana entre Verdad y Mentira y el mito de Horus y Seth?

Creo que, en este punto, una consideración de Claude Lévi-Strauss puede ser de utilidad. Discutiendo la obra de Vladimir Propp acerca de los cuentos populares rusos y las relaciones entre cuentos y mitos, LéviStrauss (1979 [1973]: 125) señala que

“...el mitógrafo advierte casi siempre que, con forma idéntica o transformada, los mismos personajes, los mismos motivos reaparecen en los mitos y los cuentos de una población. [...] No es dudoso, sin embargo, que casi todas las sociedades perciben los dos géneros como distintos, y que la constancia de esta distinción se explica por alguna causa. A nuestro juicio, tal fundamento existe, pero se reduce a una diferencia de grado que es doble. En primer término, los cuentos están construidos sobre oposiciones más débiles que las que se encuentran en los mitos: no ya cosmológicas, metafísicas o naturales, como en estos últimos, sino más frecuentemente locales, sociales o morales. En segundo término, y precisamente porque el cuento consiste en una transposición debilitada de temas cuya realización ampliada es lo propio del mito, el primero está sometido menos estrictamente que el segundo, al triple respeto de la coherencia lógica, la ortodoxia religiosa y la presión colectiva” 15 .

La consideración de Lévi-Strauss puede ser de interés en tanto y en cuanto destaca que la diferencia entre mito y cuento es una diferencia de grado, y que, en el marco de esa distancia gradual, puede haber espacio para las transformaciones de los personajes y los motivos míticos, que devendrían más locales, sociales y morales, que cosmológicos, metafísicos y naturales. En lo que respecta a las relaciones de Verdad y Mentira con el mito de Horus y Seth, puede así advertirse que la transformación de los dioses en conceptos abstractos personificados que involucran lo verdadero (MAat) y lo falso $(\mathrm{Grg})$ traspone el antagonismo desde un plano situado en el mundo de los dioses a otro que sucede en un contexto más deliberadamente humano, y desde una escala cosmológica a otra de tipo moral. Como el propio Baines (1996:374) apunta, "el tratamiento [de $V$ erdad y Mentira] también trae elementos morales a la superficie, transformando eventos en señales de dilemas morales generales".

En este punto, la conexión de ambos textos con el mito de Horus y Seth se advierte con mayor claridad. Tanto uno como otro pueden lícitamente ser interpretados como realizaciones literarias del mismo mito. En referencia a La contienda, la presencia de los dioses mismos hace que la dimensión mitológica del relato 
sea más visible; sin embargo, también es visible su dimensión literaria, tanto por el añadido de contenidos no-canónicos como por el uso selectivo de las formas narrativas y los juegos de palabras que aparecen a lo largo del texto. En cuanto a Verdad y Mentira, si el aspecto literario parece más visible que el mitológico, debe recordarse que el esquema formal del relato procede del canon mítico sobre los conflictos que oponen a Osiris con Seth, y luego a este último con Horus, y que esa mayor lejanía es razonablemente comprensible en la distancia de grado que separa al cuento del mito. En todo caso, más cerca o más lejos del topos mítico, La contienda entre Horus y Seth y el relato de Verdad y Mentira presentan dos formas de lo que, utilizando términos de Loprieno, es posible reconocer como una exploración mimética del topos ${ }^{16}$, dos huellas de actividad intelectual específica en el Egipto de tiempos ramésidas.

\section{De los MOdOS DE RESOLVER LOS CONFLICTOS}

La segunda cuestión referida a estos dos textos que me interesa señalar refiere, más de lleno, al contenido de ambos relatos. Específicamente, se trata de considerar los principios que rigen los procedimientos a través de los cuales se pretende dirimir los conflictos y establecer la justicia. En efecto, si un denominador común recorre ambos textos, éste refiere no sólo a los antagonismos entre sus protagonistas sino también a la búsqueda por alcanzar soluciones para los conflictos que los enfrentan.

Según se indicaba más arriba, un elemento invariable en ambos relatos facilita un punto de partida para este análisis: tanto en La contienda como en Verdad y Mentira es la Enéada la que -en su carácter de grupo colegiado- considera los reclamos de Horus y de Seth en pos de acceder a la realeza, así como los de Mentira ante la hipotética falta cometida por Verdad, y los del hijo de Verdad en su determinación por reivindicar a su padre. El carácter judicial de esas escenas, a priori, parece seguro. Y, tomando en cuenta la época de redacción de ambos textos, esas escenas podrían remitir a los procedimientos judiciales efectivamente realizados por las cortes estatales del Reino Nuevo (cf. Allam, 1977: 536-553; Lorton, 1977: 2-64; Tyldesley, 2001: 60-76). Sin embargo, es necesario avanzar aquí con prudencia.

Los procedimientos judiciales de la Enéada del relato de La contienda -a los que se ha dedicado un estudio aparte (Campagno, 2004: 109-137; 2006a: 211-226; 2006b: 20-33)- distan sensiblemente de aquellos celebrados por el Estado de la época. Si algo caracteriza a la Enéada en este relato, son sus continuas tribulaciones y su incapacidad para imponer sus veredictos, cuando tiende a favorecer a Horus por sobre su oponente. En efecto, Seth rechaza sistemáticamente los intentos de consagrar a Horus en el trono de su padre, y reclama nuevas instancias judiciales, a las que la Enéada accede una y otra vez. Por otra parte, tampoco logra poner orden ante las trampas que los opositores se tienden el uno al otro en las competencias a los que se los somete, y ni siquiera consigue sancionar a Horus, luego de que éste agrede a su propia madre. Ahora bien, esa Enéada vacilante y perpleja, que podría ser interpretada en el marco de la mimesis, de la creación literaria del autor de esta versión del conflicto entre Horus y Seth, no necesariamente implica la presencia de un actor impotente en el relato. Si esta Enéada parece no lograr que su voluntad se imponga, esto sucede porque, en los episodios recién mencionados, carece del monopolio de la coerción, atributo indispensable para una corte judicial estatal.

La carencia del monopolio de la coerción por parte de una corte judicial, sin embargo, sólo constituye una situación absurda en el marco de un dispositivo judicial estatal. Existen otros modos de organización social -como el que corresponde a las sociedades no-estatales, en los que el parentesco proporciona la lógica dominante- en los que tal monopolio no se halla presente. En tales condiciones, las formas de resolución de conflictos suelen involucrar extensas negociaciones. Los líderes y los consejos aldeanos median entre las partes, y usualmente se alcanza algún tipo de consenso. Pero este puede demorarse largamente, en especial, en los casos en que las partes en pugna no ceden fácilmente en sus reclamos. Es este tipo de lógica de resolución de conflictos el que -abundantemente documentado etnográficamente y también reconocible en ámbitos locales del Antiguo Egipto- parece estar operando en la mayor parte de los procedimientos judiciales que 
se advierten en la narración ${ }^{17}$. Así, del mismo modo que en las sociedades no-estatales y las comunidades aldeanas egipcias, la lógica del parentesco ocupa un lugar de relevancia en la estructuración del relato de $L a$ contienda.

Pero tal preponderancia de una dinámica judicial asociada al parentesco no excluye momentos en los que emerge un tipo de judicialidad propiamente estatal. En este sentido, se destacan dos episodios. Por un lado, el castigo físico al que se somete al barquero Anty, luego de que éste, desobedeciendo una orden expresa de la Enéada, traslada a Isis a la Isla del Medio. Y por otro, el final de la narración en el que, luego de la intervención del propio Osiris, Atum-Ra y la Enéada logran que se le imponga a Seth -reducido a la condición de prisionero- el fallo favorable a Horus. Se trata de dos episodios que no se superponen de modo confuso al predominio global de la lógica parental, el primero de ellos porque opera sobre un sirviente y no sobre los protagonistas del juicio; y el segundo, porque en ese momento la lógica del parentesco es desplazada del centro de la escena por la lógica estatal, que es la que finalmente prevalece en la resolución del conflicto. Así pues, en el relato de La contienda es posible advertir dos tipos de procedimientos judiciales divergentes, asociados uno a la lógica del parentesco y el otro a la lógica del Estado.

¿Y qué sucede en el relato de Verdady Mentira acerca de este tipo de procedimientos? La Enéada también aparece aquí, tanto en el fragmentario inicio como en el también incompleto final del texto. A pesar de las lagunas, sin embargo, esa Enéada parece sensiblemente diferente de la que se describe en La contienda. En efecto, en ambos episodios, la Enéada aparece imponiendo sumariamente el castigo -primero a Verdad, luego a Mentira- sin lugar a vacilaciones propias ni a reclamos ajenos. En el primero de ellos, la ejecución de la pena es inmediata:

"Entonces Mentira dijo a la Enéada: «Haced que se traiga a Verdad y se cieguen sus ojos y se lo coloque como portero de mi casa». Y la Enéada hizo todo como él dijo. (2,2-3)"

En el segundo episodio, las lagunas son mayores, pero se advierte que tanto Mentira como el hijo de Verdad realizan juramentos ante la Enéada (Théodoridès, 1969a, 85-105), y se mencionan luego cien golpes y cinco heridas, un cegamiento y la casa de Verdad (de la que Mentira habría sido reducido a la condición de portero), como castigos ejecutados sobre el vencedor del primer pleito. En este sentido, a pesar de los tratamientos sumarios, se puede notar que la Enéada no procede a negociar ni a buscar consensos y es singularmente expeditiva en la aplicación de las penas. Estos procedimientos, ciertamente, se parecen mucho más a los efectuados en las cortes estatales que a los que ejecuta la Enéada de La contienda. Se podría concluir, entonces, que los procedimientos para establecer justicia que se establecen en el relato de Verdad y Mentira fueron elaborados siguiendo un modelo exclusivamente estatal. Y esto parece así, en lo que a los procedimientos de esta Enéada concierne. Pero hay un breve pasaje, sobre el que me gustaría llamar la atención.

En el episodio de Verdady Mentira en el que el hijo de Verdad pide a su madre que le revele la identidad de su padre, la dama señala al portero ciego, sentado en la puerta de la residencia, y le indica que ese es su padre. La reacción del joven es muy significativa. Le espeta a su madre:

“«Esto merece que se reúna a la gente de tu familia (mhyt), y que se haga llamar a un cocodrilo». (6,1-2)”

¿Qué significa esta reacción, al parecer, henchida de indignación? Todo sugiere que el hijo de Verdad repudia el hecho de que su padre permanezca en su deplorable condición de portero ciego de la propia madre del joven. El hijo aborrece el hecho de que sea su madre quien tiene reducido a su padre a una condición servil, lo que, por otra parte, implica que ésta le ha negado al hijo el acceso a la figura paterna, lo que lo acerca a la condición del huérfano ${ }^{18}$. Ante todo ello, el hijo de Verdad parece sostener, aunque de un modo algo críptico, que su madre debería ser severamente castigada. Pero he aquí que, a pesar de que la dinámica judicial asociada a la Enéada es decisiva en el relato, el joven invoca un procedimiento sensiblemente divergente: convocar a la parentela y a un cocodrilo. La mención es oscura, pero es posible pensar algo acerca de ella. 
La alusión al cocodrilo parece comprensible, si se consideran diversos paralelismos procedentes de otros textos. Se sabe bien que el cocodrilo era un animal tan reverenciado como temido por los antiguos egipcios, y existen relatos en los que el cocodrilo es señalado como el destino anunciado (Elpríncipe predestinado 19 ) o concretado (la muerte del rey Actoes según Manetón ${ }^{20}$ que pone fin a la existencia de una persona. Es, sin embargo, en dos de los relatos del papiro Westcar en dónde la presencia de un cocodrilo resulta más significativa $^{21}$. En efecto, en uno de ellos, la mujer del sacerdote Ubainer mantiene relaciones íntimas con un individuo de baja condición social (un nedjés) y el sacerdote crea un cocodrilo de cera que se transforma en real y captura al amante; llevados ante el rey, éste establece que el amante sea entregado al cocodrilo y la mujer sea entregada al fuego. En el final de otro relato, referido al nacimiento prodigioso de los reyes de la Dinastía $\mathrm{V}$, una criada intenta - para vengarse de su patrona, quien la ha golpeado- denunciar ante el rey los prodigios que ha presenciado; al referirle la intención a su propio hermano, éste reacciona golpeándola, y cuando la criada va al río a buscar agua, un cocodrilo la atrapa. De este modo, es posible admitir que la referencia que el hijo de Verdad hace al hecho de traer un cocodrilo, se refiere al castigo que merece su madre: ser devorada por el animal ${ }^{22}$.

Ahora bien, ¿qué hay de la parentela? ¿Por qué el hijo de Verdad considera que, antes que el cocodrilo, debería ser convocada la gente de la familia? Los paralelismos se hacen aquí menos visibles. Sin embargo, un elemento del último relato referido, quizás, ofrece alguna pista. Antes que la criada sea atacada en el río por el cocodrilo, encuentra a su hermano y le expone el plan de delatar a Redyedet, su patrona. Y el hermano reacciona violentamente, censurando la idea, reprochándole que lo involucre y azotándola con una vara de lino. Ante lo que el hombre juzga como un acto reprobable de su hermana -se trata de una falta respecto del vínculo de patronazgo que la une a Redyedet-, ejecuta directamente un castigo (que luego se complementa -si se quiere, “cósmicamente" - con el ataque del cocodrilo) ${ }^{23}$. Quisiera enfatizar aquí la identidad de aquél que decide y ejecuta el castigo: un hermano.

Considérese ahora la situación desde otro punto de vista: según se apuntaba más arriba, los indicios acerca de los dispositivos judiciales a la escala local en el Antiguo Egipto convergen en el sentido de que los asuntos comunales normalmente eran resueltos en el interior de la comunidad y la justicia estatal sólo intervenía en aquellos casos que no lograran ser resueltos allí o en los que el Estado se viera directamente afectado (Théodoridès, 1969b; Trigger, 1993: 47; Allam, 1995: 49; Eyre, 1999: 44; Campagno, 2004: 132). Esa justicia a escala local parece haber operado en función de la lógica dominante en tales ámbitos, vale decir, aquella que se relaciona con la práctica del parentesco. Esto significa que, a la escala global de la sociedad egipcia, convivían dos dispositivos judiciales, que operaban en contextos sociales diferentes, de acuerdo con el predominio de la lógica estatal o de la lógica parental. Y, más allá de los contextos concretos, ambas lógicas podían dejar sus huellas en otros ámbitos, tales como el de las representaciones acerca del mundo de los dioses, y también podían servir de modelos para la elaboración de narraciones referidas a las divinidades tanto como a la sociedad de los seres humanos. De hecho, se ha visto ya cómo ambas lógicas operan conjuntamente en la estructuración del relato de La contienda entre Horus y Seth.

En este sentido, es posible considerar que la referencia del hijo de Verdad a la convocatoria de la parentela implique que es en el marco de tal grupo en el que debe juzgarse la inconducta de su madre ${ }^{24}$. En efecto, todo parece sugerir que el joven censura a su madre porque ésta ha despreciado las normas que corresponden a las relaciones entre progenitores, vale decir, normas compatibles con la lógica del parentesco. Y tal parece que, ante esa falta, el tribunal de la Enéada -que aquí opera según procedimientos estatales- no es una instancia competente. En su lugar, es la gente de la familia la que debe intervenir. Como sucede con el hermano de la criada de Redyedet, es el grupo parental el que se halla habilitado para determinar el castigo a una falta que, aunque de gravedad, corresponde al ámbito "doméstico" 25.

Así pues, tanto el relato de La contienda entre Horus y Seth como el de Verdad y Mentira permiten advertir la misma duplicidad en el plano de principios que rigen los procedimientos para resolver conflictos 
y administrar justicia, una duplicidad que -a su vez- remite a la coexistencia de dos lógicas de organización social en el Antiguo Egipto, asociadas al parentesco y al Estado. Tal característica común no parece mera coincidencia: por lo contrario, parece lo más esperable si se toma en cuenta el mismo contexto sociocultural general de sus redactores (la comunidad de Deir el-Medina) y el hecho de que entre ambos relatos, y siguiendo a Lévi-Strauss, la diferencia no es radical sino de grado.

\section{CODA}

Retorno a El-Shamy. De acuerdo con el folklorista egipcio, el cuento del vil tintorero Abu-Qir y el noble barbero Abu-Sir, incluido en Las Mil y Una Noches, representa una variante de un tipo de cuento popular (tipo 613, en la clasificación de los folkloristas), que remite a "modernas variaciones del 'mito'/ relato sagrado' del Antiguo Egipto de 'Verdad y Mentira' y 'La contienda entre Horus y Seth'”. Según señala el autor, en las culturas populares contemporáneas relacionadas con el mundo árabe, el tipo 613 se titula "El Noble y el Vil", un cuento que relata "cómo una persona malvada mutila y ciega a un compañero (o bermano) de buen corazón, y el eventual triunfo del bien sobre el mal". El-Shamy concluye que "la estructura general y las creencias asociadas con el relato egipcio antiguo todavía viven en las tradiciones orales actuales de Egipto" (El-Shamy, 2006, 34-36; cf. 1980, 261-264). Si tal fuera el caso, tal vez podría advertirse aquí esa trasposición que procede del mito al cuento y que, como señalaba Levi-Strauss, conduce de reflexiones "cosmológicas, metafísicas o naturales" a otras "locales, sociales o morales". Tal vez lo más perdurable del mito de Horus y Seth no haya sido el plano divino de los dioses en pugna sino la reflexión sobre las formas de lo justo y lo injusto, y sobre los modos de intervenir en esa tensión.

\section{Bibliografía}

Allam, S. Gerichtsbarkeit, en: Helck, W., Otto, E. y Westendorf, W. (eds.), Lexikon der Ägyptologie, vol. 2, Wiesbaden, Otto Harrassowitz, 1977, pp. 536-553.

Allam, S. Quenebete et administration autonome en Égypte pharaonique, Revue Internationale des Droits del'Antiquité 42, 1995, pp. 11-69.

Assmann, J. Die Verborgenheit des Mythos in Ägypten, Göttinger Miszellen 25, 1977, pp. 7-43.

Aufrère, S. Dans les marécages et sur les buttes. Le crocodile du Nil, la peur, le destin et le châtiment dans l'Égypte ancienne, Égypte Nilotique et Méditerranéenne 4, 2011, pp. 51-79.

Baines, J. Myth and literature, en: Loprieno, A. (ed.) Ancient Egyptian Literature. History and Forms, Probleme der Ägyptologie 10, Leiden, E. J. Brill, 1996, pp. 361-378.

Blackman, A.M. The Story of King Kheops and the Magicians Transcribed from Papyrus Westcar (Berlin Papyrus 3033), ed. W.V. Davies. Reading, J.V. Books, 1988.

Bohannan, P. The Differing Realms of the Law, en: Bohannan, P. (ed.), Law and Warfare. Studies in the Anthropology of Conflict, New York, The Natural History Press, 1967, pp. 43-56.

Broze, M. Mythe et roman en Égypte ancienne. Les aventures d'Horus et Seth dans le Papyrus Chester Beatty I, Orientalia Lovaniensia Analecta 76, Leuven, Peeters, 1996.

Brunner-Traut, E. Ältagyptische Märchen, Düsseldorf, E. Diederichs, 1965.

Campagno, M. Una lectura de «La contienda entre Horus y Seth», Buenos Aires, Universidad de Buenos Aires / Ediciones del Signo, 2004.

Campagno, M. Crimen y castigo en «La contienda entre Horus y Seth», en: Campagno, M. (ed.), Estudios sobre parentesco y Estado en el Antiguo Egipto, Buenos Aires, Universidad de Buenos Aires / Ediciones del Signo, 2006a, pp. 211-226. 
Campagno, M. Judicial Practices, Kinship and the State in «The Contendings of Horus and Seth», Zeitschrift für Agyptische Sprache und Altertumskunde 133, 2006b, pp. 20-33.

Díaz Rivas, H. Horus, el huérfano, Trabajos de Egiptología 5, 2009, pp. 183-190.

Díaz Rivas, H. Creciendo sin padre en la literatura egipcia, en: Burgos Bernal, L., Pérez Largacha, A. y Vivas Sainz, I. (eds.), Actas V Congreso Ibérico de Egiptología. Cuenca, 9-12 de marzo de 2015, Cuenca, Ediciones de la Universidad de Castilla la Mancha, 2017, pp. 789-800.

Dorson, R.M. Foreword, en El-Shamy, H., op. cit., 1980, pp. ix-xxxix.

El-Shamy, H.M. Folktales of Egypt, Chicago, The University of Chicago Press, 1980.

El-Shamy, H.M. Oral Traditional Tales and the Thousand Nights and a Night: The Demographic Factor, en: Nøjgaard, M., de Mylius, J., Piø, I. y Holbeck, B. (eds.), The Telling of Stories: Approaches to a Traditional Craft, Odense, Odense University Press, 1990, pp. 63-117.

El-Shamy, H.M. Introduction to This Edition and Classification by Tale-Type and Motif of Maspero's Popular Stories of Ancient Egypt, en: Maspero, G., Popular Stories of Ancient Egypt, Santa Barbara / Denver / Oxford, ABCCLIO, 2002, pp. vii-xc.

El-Shamy, H.M. Mythological Constituents of Alf Laylah wa Laylah, en: Yamanaka, Y.y Nishio, T. (eds.), The Arabian Nights and Orientalism: Perspectives from East and West, London, I.B. Tauris, 2006, pp. $25-46$.

Eyre, Ch.J. Fate, Crocodiles and the Judgement of the Dead. Some Mythological Allusions in Egyptian Literature, Studien zur Altägyptischen Kultur 4, 1976, pp. 103-114.

Eyre, Ch.J. Crime and Adultery in Ancient Egypt, Journal of Egyptian Archaeology 70, 1984, pp. 92-105.

Eyre, Ch.J. Yet Again the Wax Crocodile: P.Westcar 3, 12ff, Journal of Egyptian Archaeology 78, 1992, pp. 280-281.

Eyre, Ch.J. The Village Economy in Pharaonic Egypt, en: Bowman, A. y Rogan, E. (eds.) Agriculture in Egypt. From Pharaonic to Modern Times, Oxford, Oxford University Press, 1999, pp. 33-60.

Franke, D. Altägyptische Verwandtschaftsbezeichnungen in Mittleren Reich, Hamburg, Verlag Borg GmbH, 1983.

Galán, J.M. Cuatro viajes en la Literatura del Antiguo Egipto, Madrid, CSIC, 1998.

Gardiner, A.H. The Library of A. Chester Beatty. Description of a Hieratic Papyrus with a Mythological Story, Love Songs, and Other Miscellaneous Texts, $N^{\circ} 1$ ), London, The Oxford University Press, 1931.

Gardiner, A.H. Late-Egyptian Stories, Bruxelles, Éditions de la Fondation Égyptologique Reine Élisabeth, 1932.

Gardiner, A.H. Hieratic Papyri in the British Museum. Third Series: Chester Beatty Gift, 2 vols., London, British Museum, 1935.

Gwyn Griffiths, J. The Conflict of Horus and Seth from Egyptian and Classical Sources, Liverpool, Liverpool University Press, 1960.

Gwyn Griffiths, J. Allegory in Greece and Egypt, Journal of Egyptian Archaeology 53, 1967, pp. 79-102.

Jannsen, J.J. Marriage Problems and Public Reactions. en: Baines, J. et al. (eds.), Pyramid Studies and Other Essays presented to I. E. S. Edwards, London, The Egypt Exploration Society, 1988, pp. 134-137.

Junge, F. Mitos und Literarizität: Die Geschichte vom Streit der Götter Horus und Seth, en: Behlmer, H. (ed.), ...Quarentes Scientiam. Festgabe für Wolfhart Westendorf zu seinem 70. Geburtstag, Göttingen, Seminar für Ägyptologie und Koptologie, 1994, pp. 83-101.

Koenig, I. Notes sur la découverte des Papyrus Chester Beatty, Bulletin de l'Institut Français d'Archeologie Orientale 81, 1981, pp. 41-43.

Lefebvre, G. Un conte égyptien: Vérité et Mensonge, Revue d'Égyptologie 4, 1940, pp. 15-25.

Lefebvre, G. Romans et Contes Égyptiens, Paris, Librairie Adrien-Maisonneuve, 1949.

Lesko, L. Three Late Egyptian Stories Reconsidered, en: Lesko, L. (ed.), Egyptological Studies in Honour of Richard A. Parker, Hannover, University Press of New England, 1986, pp. 98-103.

Lévi-Strauss, C. La estructura y la forma. Reflexiones acerca de una obra de Vladimir Propp, en: Lévi-Strauss, C., Antropología estructural. Mito, sociedad, humanidades, México, Siglo XXI, 1979 [ed. orig. francés, 1973], pp. 113-141. 
Lichtheim, M. Ancient Egyptian Literature, vol. 1, Berkeley, University of California Press, 1973.

Lichtheim, M. Ancient Egyptian Literature, vol. 2, Berkeley, University of California Press, 1976.

López, J. Cuentos y fábulas del Antiguo Egipto, Barcelona, Trotta, 2005.

Loprieno, A. Topos und Mimesis. Zum Ausländer in der ägyptischen Literatur, Wiesbaden, Otto Harrassowitz Verlag, 1988.

Loprieno, A. Defining Egyptian literature: Ancient texts and modern theories, en: Loprieno, A. (ed.) Ancient Egyptian Literature. History and Forms, Probleme der Ägyptologie 10, Leiden, E. J. Brill, 1996, pp. 39-58.

Loprieno, A. Prólogo, en: Campagno, M. Una lectura de «La contienda entre Horusy Seth», Buenos Aires, Universidad de Buenos Aires /Ediciones del Signo, 2004, pp. 13-20.

Lorton, D. The Treatment of Criminals in Ancient Egypt through the New Kingdom, Journal of the Economic and Social History of Orient 20, 1977, pp. 2-64.

Manetho, (ed. W.G. Waddell), Loeb Classical Library, London, William Heinemann Ltd., 1940Mathieu, 1996, 81-93.

McDowell, A. G. Village Life in Ancient Egypt. Laundry Lists and Love Songs, New York, Oxford University Press, 1999.

Meletinski, E.M. El mito. Literatura y folclore, Madrid, Akal, 2001 [1993].

Moers, G. Fingierte Welten in der ägyptischen Literatur des 2. Jahrtausends v. Chr. Grenzüberschreitung, Reisemotiv und Fiktionalität, Probleme der Ägyptologie 19, Leiden, Brill, 2001.

Oden Jr., R. "The Contendings of Horus and Seth" (Chester Beatty Papyrus No. 1): A Structural Interpretation, History of Religions 18, 1979, pp. 352-369.

Orriols-Llonch, M. Mujer ideal, mujer infractora. La transgresión femenina en el antiguo Egipto, Lectora 18, 2012, pp. $17-40$.

Orriols-Llonch, M. Crimen y castigo. El adulterio femenino en el antiguo Egipto, en: Antela-Bernárdez, B., Zaragozà Serrano, C. y Guimerà Martínez, A. (eds.), Placer y dolor. Las mujeres en la Antigüedad, UAH Monografías Humanidades 72, Alcalá de Henares, Universidad de Alcalá, 2017, pp. 13-30.

Parkinson, R.B. The Tale of Sinuhe and Other Ancient Egyptian Poems, 1940-1640 BC, Oxford, Oxford University Press, 1997.

Pestman, P. Who were the owners, in the «Community of Workmen» of the Chester Beatty Papyri?, en: Demarée, R.J. y Janssen, J.J. (eds.), Gleanings from Deir el Medina, Leiden, Nederlands Instituut voor het Nabije Oosten, 1982, pp. 155-172.

Pinch, G. Egyptian Mythology. A Guide to the Gods, Goddesses, and Traditions of Ancient Egypt, Oxford, Oxford University Press, 2002.

Pospisil, L. Law and Order, en: Clifton, J. (ed.), Introduction to Cultural Anthropology, Boston, Houghton Mifflin Co., 1968.

Quack, J.F. Der Streit zwischen Horus und Seth in einer spätneuägyptischen Fassung, en: Guermeur, I. y Zivie-Coche, Ch. (eds.), Parcourir l'éternité. Hommages à Jean Yoyotte, Vol. II, Bibliothèque de l'École Pratique des Hautes Études, sciences religieuses 156, Turnhout, Brepols Publishers, 2012, pp. 907-921.

Quirke, S. Egyptian Literature 1800 BC, Questions and Readings, London, Golden House Publications, 2004.

Roberts, S. Order, and Dispute. An Introduction of Legal Anthropology, Oxford, Martin Robertson, 1979.

Rosenvasser, A. Torneos de acertijos en la literatura del Antiguo Egipto, Buenos Aires, Maia, 1947.

Théodoridès, A. Le serment terminal de "Vérité-Mensonge", Revue d'Égyptologie 21, 1969a, pp. 85-105.

Théodoridès, A. Les ouvriers- “magistrats" en Égypte à l'époque ramesside (XIXe-Xxe dyn.; 13e-10e s. av. J.-C.), Revue Internationale des Droits de l'Antiquité 16, 1969b, pp. 103-188.

Thompson, S. The Folktale, New York, Dryden Press, 1946.

Trigger, B.G. Early Civilizations. Ancient Egypt in Context, Cairo, American University in Cairo Press, 1993.

Tyldesley, J. Judgement of the Pharaoh. Crime and Punishment in Ancient Egypt, London, Phoenix, 2001. 
Van Dijk, J. Myth and Mythmaking in Ancient Egypt, en: Sasson, J.M. (ed.), Civilizations of the Ancient Near East, Vol. III, New York, Charles Scribner's Sons, 1995, pp. 1697-1709.

Verhoeven, U. Ein historischer "Sitz im Leben" für die Erzählung von Horus und Seth des Papyrus Chester Beatty I, en: Schade-Busch, M. (ed.), Wege Öffnen. Festschrift für RolfGundlach zum 65. Geburstag, Wiesbaden, Harrassowitz Verlag, 1996, pp. 347-363.

Wente, E. The Contendings of Horus and Seth, en: Simpson, W.K. (ed.), The Literature of Ancient Egypt. An Anthology of Stories, Instructions, and Poetry, New Haven, Yale University Press, 1972a, pp. 108-126.

Wente, E. The Blinding of Truth by Falsehood, en: Simpson, W.K. (ed.), The Literature of Ancient Egypt. An Anthology of Stories, Instructions, and Poetry, New Haven, Yale University Press, 1972b, pp. 127-132.

Zecchi, M. Sobek, the Crocodile and Women, Studi di Egittologia e di Papirologia 1, 2004, pp. 149-153.

\section{Notas}

1 Stith Thompson (1946: 273-276) incluye algunos pasajes procedentes de relatos del Egipto antiguo entre sus motivos folklóricos. Cf. Dorson, 1980: ix-xii.

2 El-Shamy (1990, 63-117) refiere que el tópico folklórico que enfrenta al noble con el vil también aparece en Las Mil y Una Noches, en el cuento de Abu-Qir y Abu-Sir, que opone un deshonesto tintorero a un honesto barbero. Aquí el tercero que define es el rey, quien primero -instigado por el tintorero- emite una sentencia de muerte contra el barbero, en tanto que, cuando la verdad se revela, decreta la muerte del tintorero.

3 Manuscrito: p.Chester Beatty I (Dublin, Chester Beatty Library Pap. 1 Vo D). Texto: Gardiner, 1931: 8-26; 1932: 37-60. Traducciones: Lefebvre, 1949: 178-203; Wente, 1972a: 108-126; Lichtheim, 1976: 214-223; Broze 1996: 13-127 (aquí y en las siguientes notas se citan sólo algunas traducciones de referencia). En español: Rosenvasser, 1947: 29-46; Campagno, 2004: 37-63; López, 2005: 161-181.

4 Manuscrito: p.Chester Beatty II (BM 10682). Texto: Gardiner, 1932: 30-36; 1935: 1-4. Traducciones: Gardiner, 1935: 2-6; Lefebvre, 1949: 159-168; Wente, 1972b: 127-132; Lichtheim, 1976: 211-214. En español: Rosenvasser, 1947: 23-27; López, 2005: 153-160.

5 He analizado este relato en forma exhaustiva en Campagno, 2004. Remito a este trabajo para mayores referencias bibliográficas.

6 La oposición se entabla aquí entre MAat y Grg, "Verdad" y "Mentira", como corrientemente se los traduce al español, o quizás mejor "Verdad" y "Falsedad", si se interpreta este último concepto en su sentido básico de "falta de verdad", con independencia de la intención deliberada de expresarse de modo contrario a lo que se sabe, se cree o se piensa, que usualmente involucra el término "mentira".

7 El paralelismo general en el argumento de ambos relatos ha sido observado, entre otros, por Gardiner (1935, 2-6), Rosenvasser (1947, 10-14), Lefebvre (1949, 159-161), Brunner-Traut, 1965, 262; Gwyn Griffiths (1967, 90), Lesko (1986, 100), van Dijk (1995, 1703), López (2005, 153-155).

8 Lefebvre $(1949,161)$ y López $(2005,155)$ han destacado las fuertes diferencias entre la fiel y protectora Isis y esta desaprensiva dama ("una Isis indigna", según Lefebvre). Sin embargo, no habría que perder de vista el hecho de que ambos personajes femeninos conciben un hijo con quien ya ha sufrido la violencia digitada por su antagonista, y el hecho de que, tanto en La contienda como en Verdad y Mentira, aparece una escena en la que el hijo vengador reacciona contra su madre (el decapitamiento de Isis por Horus, luego de la competencia de los hipopótamos; la consideración de que la dama debería ser ejecutada, luego de que el hijo se entera de la identidad de su padre [véase infra]). Por lo demás, como plantea Baines $(1996,374)$, en ambos textos, el personaje femenino "aporta el vinculo necesario entre las generaciones $y$ motiva buena parte de la acción".

9 Acerca de la datación de La contienda en el marco del ascenso al trono de Ramsés V, cf. Verhoeven, 1996, 347-363. Sobre la datación de Verdad y Mentira en la Dinastía XIX, cf. Gardiner, 1935, 2.

10 Tal es el modo en que Lefebvre $(1949,159)$ define a estos singulares contendientes. Gardiner $(1935,6)$, seguido en este punto por Wente (1972a, 104) y por Pinch $(2002,28)$, había sugerido que el relato podría constituir un tipo de alegoría. Sin embargo, como indica Gwyn Griffiths $(1967,89-91)$, no es la narración la que ofrece un contenido alegórico sino, en todo caso, sólo los nombres de los dos protagonistas.

11 Respecto de la extensa serie de referencias a las disputas entre Horus y Seth desde los Textos de las Pirámides hasta las obras de los clásicos, cf. Gwyn Griffiths, 1960; Quack, 2012.

12 De acuerdo con Loprieno (1996: 39-58), el criterio de ficcionalidad del texto literario remite al carácter autoreferencial del texto, que implica un acuerdo entre el autor y el lector acerca del hecho de que el mundo del relato no necesariamente refiere al mundo real; el criterio de intertextualidad remite a la existencia de un "universo de textos" con el que el relato 
se vincula, lo que supone que un texto literario nunca se halla en aislamiento total, como absoluta creación de su autor; y el criterio de recepción indica que, para considerar el status literario de un texto, debe existir un dispositivo que posibilite su lectura y transmisión. Para una actualización de estos asuntos, cf. Moers, 2001.

13 Cf. por ejemplo, las posiciones de Oden, para quien "un mito tiene que tener un carácter tradicional; tiene que tener un argumento; y sus protagonistas tiene que ser de un cierto tipo. «La contienda entre Horus y Seth» coincide con todos estos criterios admirablemente" (1979, 353), y la de Junge, para quien "la historia de la contienda entre Horus y Seth por la realeza no es un mito en forma literaria sino, por el contrario, una obra de literatura ficcional" $(1994,101)$.

14 También Loprieno $(1996,50)$ enmarca el relato de Verdad y Mentira en el campo de la literatura mitológica.

15 En una línea compatible, cf. Meletinski, 2001 [1993], 247: "La semántica del cuento únicamente puede comprenderse a partir de los datos mitológicos, porque se trata de la misma semántica mitológica sólo que sometida a los dictados del código «social»".

16 Según Loprieno $(1996,55)$, "la aplicación de formas canónicas a contenidos contra-canónicos (o viceversa) permite al autor explorar las fronteras de la ideología”. Acerca de la distinción entre topos y mimesis, cf. Loprieno, 1988. 1-21.

17 Acerca de los procedimientos judiciales en sociedades no-estatales y las dificultades para imponer los veredictos, cf. Bohannan, 1967: 52-53; Pospisil, 1968: 220-221; Roberts, 1979: 124-125. Acerca de similares contextos para la administración de justicia en contextos locales en el Antiguo Egipto (con referencia a la comunidad de Deir el-Medina), cf. Eyre, 1984: 102; McDowell, 1999: 171.

18 Sobre la cuestión de la orfandad en el Antiguo Egipto, cf. Díaz Rivas, 2009; 2017.

19 Manuscrito: p.Harris 500 (BM 10060). Texto: Gardiner, 1932: 1-9. Traducciones: Lefebvre, 1949: 114-124; Lichtheim, 1976: 200-203. En español: Galán, 1998: 153-157; López, 2005: 117-124.

20 Cf. Manetho, ed. Waddell, 1940: 60-63.

21 Manuscrito: p.Westcar (p.Berlín 3033). Texto: Blackman, 1988. Traducciones: Lefebvre, 1949: 70-90; Lichtheim, 1973: 215-222; Parkinson, 1997: 102-127; Quirke, 2004: 77-89. En español: Rosenvasser, 1976: $91-96$ (sólo el cuarto cuento); López, 2005: 87-104.

22 Tal es la conclusión a la que llegan Lefebvre (1940: 23) Rosenvasser (1947: 25 nota 7), Wente (1972b: 130 nota 7) y Lichtheim (1976: 212 nota 4). Cf. también Eyre, 1976: 112-113. Sobre la cuestión del cocodrilo en el contexto de procedimientos de justicia, cf. también Eyre, 1992; Zecchi, 2004; Aufrère, 2011; Orriols-Llonch, 2017.

23 La conexión entre el cocodrilo y el destino mortal de un individuo ha sido considerada por Eyre (1976: 103-114).

24 En este sentido, cf. la posición de Mat'e, quien indica que "en la medida en que un hijo amenaza con conducir a su madre a una corte de sus parientes, podemos concluir que una mujer que violab a los deberes de una esposa era sometida a una corte de su parentela" (citado en Franke, 1983: 188).

25 Quizá se pueda suponer algo similar respecto de un episodio registrado en el p.BM 10416, en el que, ante un caso de adulterio, los allegados a la mujer engañada pretenden castigar a la adúltera y claman: "vamos a golpearla, junto con su gente (1.3)". Si bien Jannsen (1988: 137) infiere que el grupo intenta castigar a la adúltera tanto como a su parentela, creo que lícitamente se podría interpretar que ambos grupos participarán en el castigo de la mujer que ha violado las normas: se trataría, aquí también de un castigo privativo del ámbito doméstico. Respecto de los modos de tratar el adulterio, sin considerarlo un "crimen" pero admitiendo la reacción violenta de los individuos o grupos implicados, cf. Eyre, 1984: 102-103; Orriols-Llonch, 2016; 2017. 